DP -1468

- Distribution Category: UC-38

\section{A LOW-PRESSURE HYDRAULIC TECHNIQUE FOR SLURRYING RADIOACTIVE SLUDGES IN WASTE TANKS}

by

R. F. Bradley, F. A. Parsons, C. B. Goodlett, and R. M. Mobley

Approved by

A. S. Jennings, Research Manager

Separations Engineering Division

Publication Date: November 1977

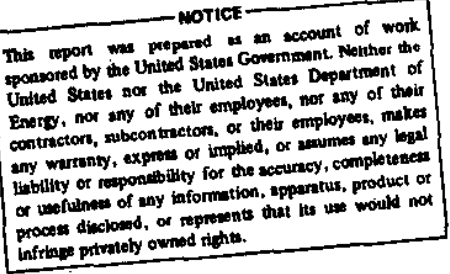

E. I. DU PONT dE NEMOURS AND COMPANY SAVANNAH RIVER LABORATORY AIKEN, SOUTH CAROLINA 29801

PREPARED FOR THE U.S. DEPARTMENT OF ENERGY UNOER CONTRACT AT(07.2):1

1. 
Present technology for the removal of sludges from radioactive liquid waste storage tanks at the Savannah River Plant (SRP) requires large volumes of fresh water added through high-pressure ( 3000 psig) nozzles positioned to resuspend and slurry the sludge. To eliminate the cost of storing and evaporating these large volumes of water (several hundred thousand gallons per tank cleaned), a technique was developed at the Savannah River Laboratory (SRL) to use recirculating, radioactive, supernate solution to resuspend the sludge. The system consists in part of a single-stage centrifugal pump operating in the sludge at 2100 psia. Recirculating supernate is drawn into the bottom of the pump and forced out through two oppositely directed nozzles to give liquid jets with a sludge-slurrying capability equal to that obtained with the present high-pressure system. In addition to eliminating the addition of large quantities of water to the tanks, the low-pressure recirculating technique requires only approximately one-sixth of the power required by the high-pressure system.

Test results with clay (as a simulant for sludge) in a waste tank mockup confirmed theoretical predictions that jets with the same momentum gave essentially the same sludge-slurrying patterns. The effective cleaning radius of the recirculating jet was directly proportional to the product of the nozzle velocity and the nozzle diameter $\left(U_{0} D\right)$. At the maximum $U_{0} D$ developed by the pump ( 14 $\mathrm{ft}^{2} / \mathrm{sec}$ ), the effective cleaning radius in the tank mockup was 20 feet. 


\section{CONTENTS}

Introduction 5
SRP Waste Storage
Sludge Removal Requirements 7
Previous Sludge Removal Experience 7
Options for Sludge Removal 9
Low-Pressure Sludge-Slurrying Concept 10
Equipment and Test Facility 13
Centrifugal Pump 13
Test Facility 20
Results of Feasibility Tests 20
Conclusions 27
References 28

1. 


\section{LIST OF FIGURES}

1 High-Heat Waste Processing in the Tank Farm 6

2 Low-Heat Waste (LAW) Processing in the Tank Farm 6

3 Cooled Waste-Storage Tanks 8

4 Uncooled Waste-Storage Tanks 8

5 High-Pressure Once-Through Technique 9

6 Low-Pressure Recirculating Techniques 10

7 Turbulent Free Jet 11

8 Discharge Nozzle of Slurrying Pump 14

9 Proposed Mounting of Slurrying Pump in Waste Tank Riser 15

10 Cooling Water Pipe and Shaft Alignment Bushings in Case Sections of Slurrying Pump 16

11 Cutless Rubber Bushing in Support Spider 17

12 Slurrying Pump Impeller (15-in. diameter) 18

13 Slip-Ring for 150-HP Motor 19

14 Pump Support Tower 21

15 Turntable and Pinion Drive 22

16 Interior of Half-Tank Mockup 22

17 Pump Discharge Pressure Versus Impeller RPM 23

18 Pump Discharge Capacity Versus Impeller RPM 23

19 Effective Cleaning Radius Increase with Increasing $\mathrm{U}_{\mathrm{O}} \mathrm{D} \quad 24$

20 Cleaning Pattern of Slurry Pump in Half-Tank Mockup 25

21 Kaolin Formation After Slurry Operation - Zone 125

22 Kaolin Formation After Slurry Operation - Zone 226

23 Kaolin Formation After Slurry Operation - Zone 326 


\title{
A LOW-PRESSURE HYDRAULIC TECHNIQUE FOR SLURRYING RADIOACTIVE SLUDGES IN WASTE TANKS
}

\author{
INTRODUCTION
}

\section{SRP Waste Storage}

Aqueous waste solutions from the processing of irradiated fuel elements at the Savannah River Plant (SRP) are stored as alkaline solutions in underground carbon steel tanks with capacities of $3 / 4$ to $1-1 / 3$ million gallons ( 2800 to $5000 \mathrm{~m}^{3}$ ). The waste, as received at the waste tank farm, consists of two phases: 1) an alkaline liquid supernate phase consisting primarily of dissolved sodium salts, including the nitrate, nitrite, carbonate, sulfate, hydroxide, and aluminate; and 2) a sludge phase consisting primarily of the relatively insoluble hydrous oxides and/or oxides or iron, aluminum, and manganese plus large amounts of interstitial supernate. The sludge initially comprises approximately $5 \%$ of the total waste volume before evaporation of the supernate. Much of the biological hazard is contained in the sludge because most of the ${ }^{90} \mathrm{Sr}$ and plutonium are found in the solids in this phase. There are presently $\sim 2$ million gal $\left(\sim 8000 \mathrm{~m}^{3}\right)$ of sludge stored in tanks at SRP.

The specific gravity of the supernate is $\sim 1.2 \mathrm{~g} / \mathrm{cm}^{3}$, and that of the solids in the sludge ranges between 1.5 to $1.8 \mathrm{~g} / \mathrm{cm}^{3}$. High-heat waste from fuel reprocessing at SRP contains most of the fission products and has a decay heat of 20.05 watts (th) per liter. Low-heat waste has a decay heat $<0.1 \%$ of that for highheat waste. Because of thermal convection in the sludge phase of high-heat waste, a period of approximately 6 months to 1 year is required before most of the sludge layer settles to the bottom of the receiving tanks. The high-heat supernate layer is then removed to a transfer tank for further sludge settling, then concentrated by evaporation, and transferred to other tanks for storage as a damp salt cake (Figure 1). The sludge phase remains in the receiving tank, and heat is continually removed by cooling coils. Sludge in low-heat waste settles more readily in the receiving tank to produce a clear supernate layer (Figure 2). There is no further processing of the sludge during tank storage. A large quantity. of supernate still remains with the sludge as interstitial liquid. (The sludge layer is 70 to $90 \%$ supernate by volume even after settling.) The settled sludge is a relatively immobile gelatinous material, typical of that obtained for settled hydrous oxides. 


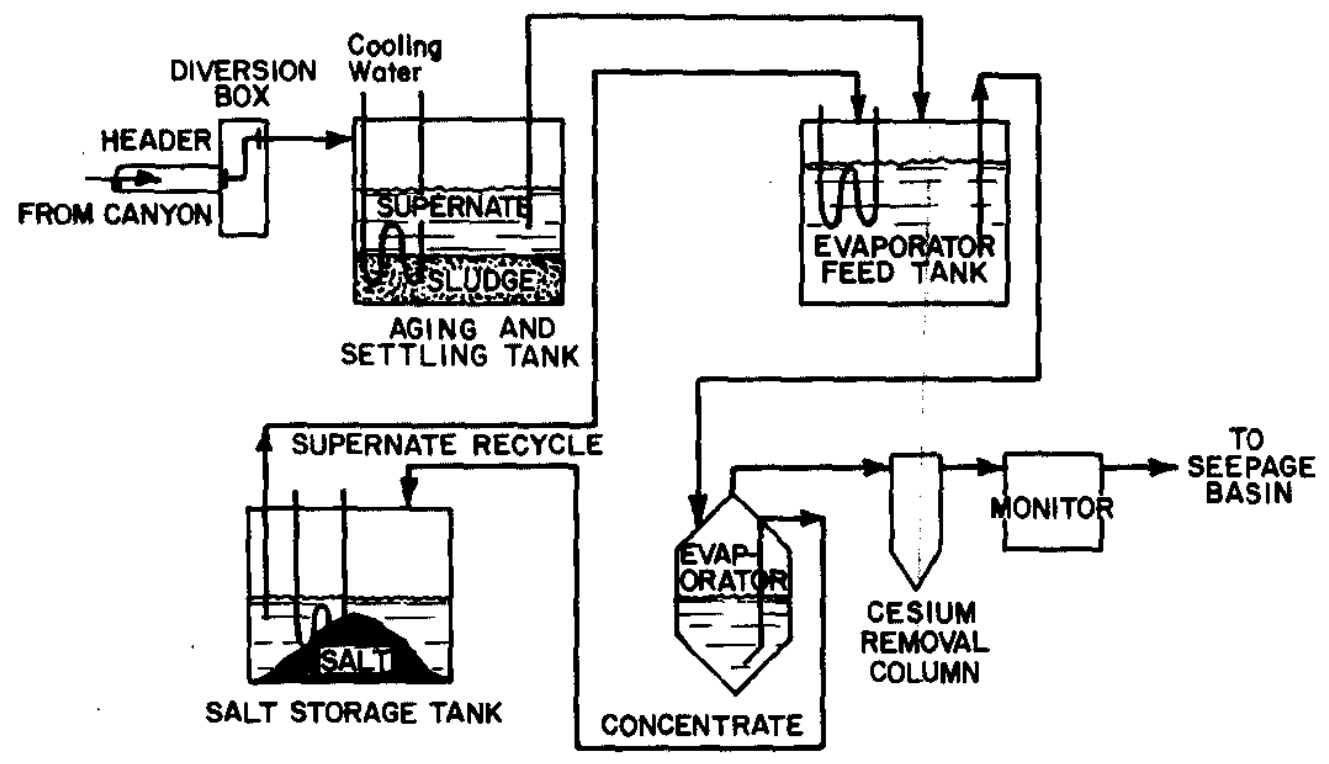

FIGURE 1. High-Heat Waste Processing in the Tank Farm

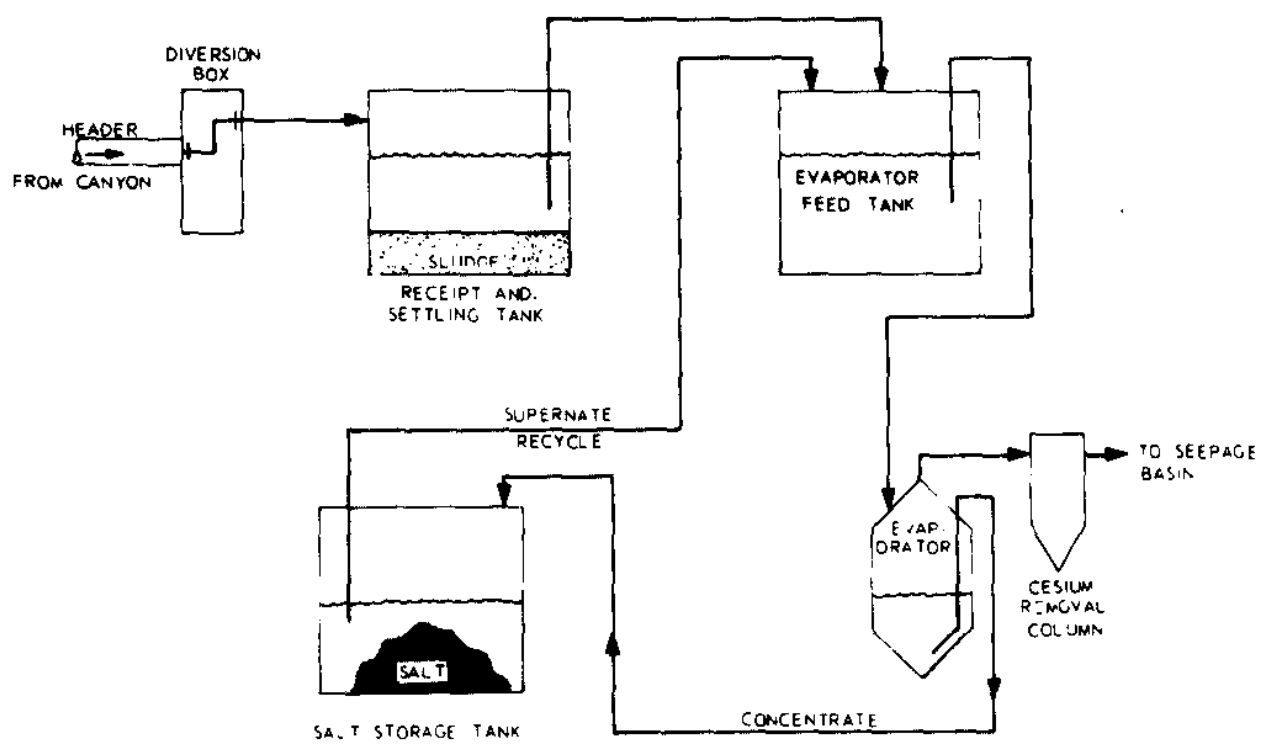

FIGURE 2. Low-Heat Waste Processing in the Tank Farm 
A1l waste tanks at SRP are built of carbon steel and reinforced concrete. Three designs (Types I, II, and III) have double steel walls and forced (water) cooling (Figure 3). The fourth tank design (Type IV) has one steel wall and no forced cooling and is used primarily for low-heat waste (Figure 4). Both Type I and Type II tanks have a network of horizontal cooling coils located close to the bottom of the tanks and a large number of bottom-supported, vertical cooling coils which made sludge removal more difficult. Future Type III waste tanks will have double-steel walls and a large number of evenly distributed, fixed, bottom-supported, vertical cooling coils.

\section{Sludge Removal Requirements}

Removal of sludge from waste tanks is required for two SRP programs. ${ }^{1}$ First, there is a near-term program to retire several of the older waste tanks at SRP, requiring that the sludge layers in these tanks be removed. Second, present plans for solidification of SRP waste require that all sludge be removed from the tanks so that the waste can be solidified and sealed in containers for long-term onsite storage or offsite shipment. Both of these programs require that essentially all of the waste be removed from the tanks. Salt cake would be redissolved in water and pumped directly from the tanks. The majority of the sludge (>95\%) would be resuspended hydraulically and pumped from the tanks. Final tank cleaning would be accomplished chemically.

Removal of sludge from the first tank scheduled for retirement is planned for 1978. Sludges would be removed from 22 additional tanks as they are retired over the next decade. Removal of sludge for solidification could begin as early as $1987 .{ }^{1}$

\section{Previous Sludge Removal Experience}

High-velocity water jets were successfully used at SRP between 1966 and 1969 to remove sludges from 7 tanks. The sludges were removed to allow storage of salt cake in these tanks. The system is shown schematically in Figure 5. The sludge was slurried with up to 6 rotating water-nozzle positions and pumped from the tanks by separate mechanical pumps. This high-velocity water jet system removed up to $95 \%$ of the sludge from the plant waste tanks. The volume of water added was approximately five times the volume of sludge removed. 


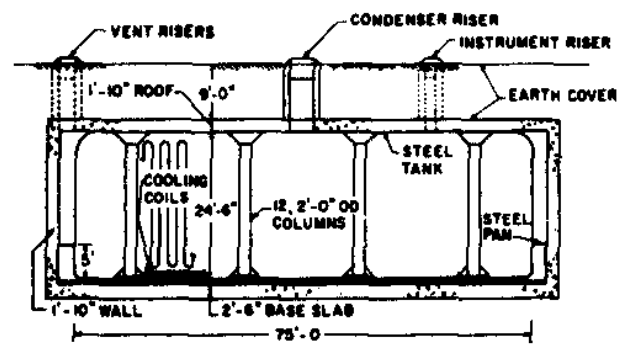

Type 1: 750,000 gallons

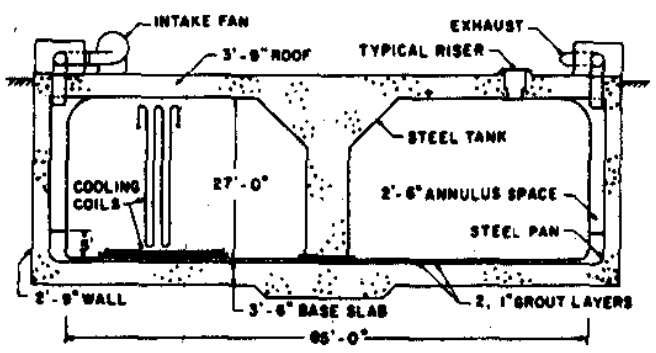

Type 11: 1,030,000 gollon:

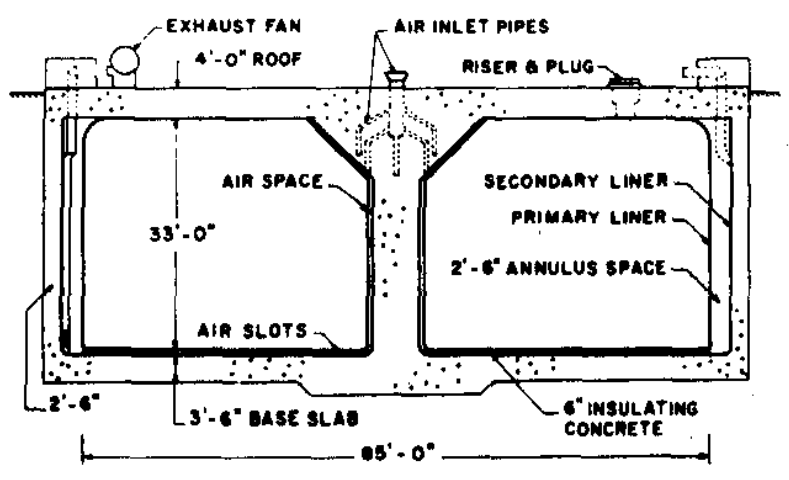

Type IIl: 1,300,000

Stressed-Relieved Primary Liner

FIGURE 3. Cooled Waste-Storage Tanks

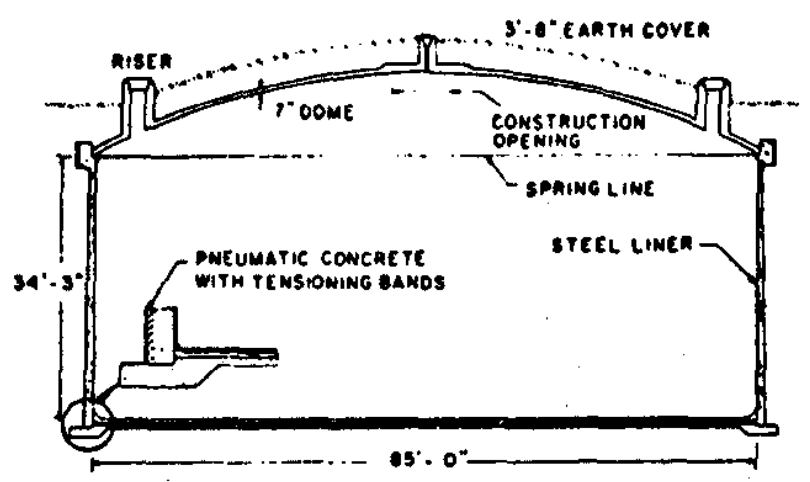

Steel Liners

Prestressed Concrete Wolls

1, 300, 000 gallons

FIGURE 4. Uncooled Waste-Storage Tanks 


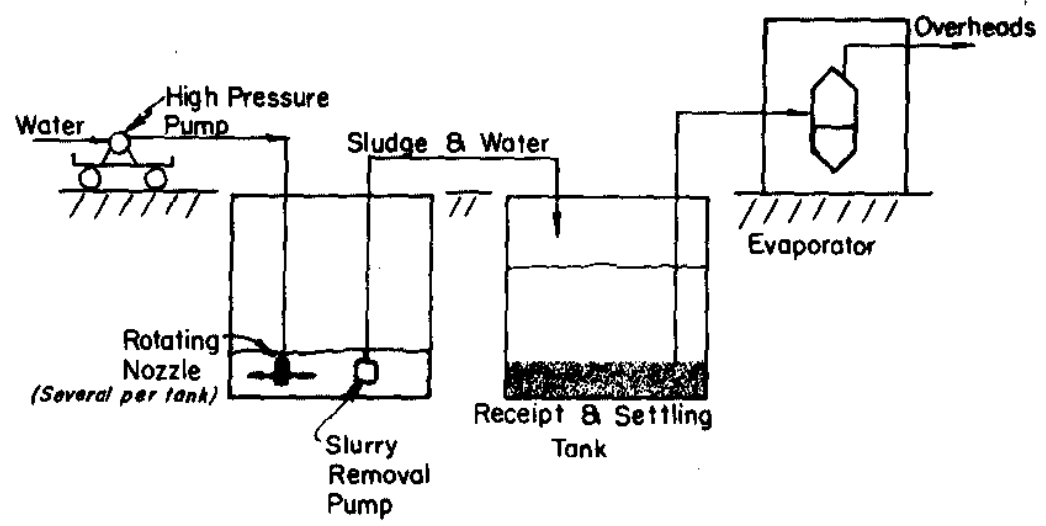

FIGURE 5. High-Pressure Once-Through Technique

The system was developed in a half-tank mockup with kaolin clay to simulate sludge. ${ }^{2}$ The tank contained support columns and bottom cooling coils. A pair of $1 / 4-i n$. -diameter $(0.63 \mathrm{~cm})$ nozzles at 3000 psig $(20 \mathrm{MPa})$ produced an effective tank bottom cleaning radius of $\sim 20 \mathrm{ft}(6 \mathrm{~m})$.

The principal drawback of this system is the need to store and evaporate the large volume of water that is added to the tanks. Because tank storage space and evaporative capacity are limited at SRP at present, the low-pressure system described in this report was developed to provide a method for suspending sludge without the large addition of water required by the highpressure system.

\section{Options for Sludge Removal}

Options for sludge removal are limited by the forest of cooling coils in many of the tanks and by the immobility of the settled sludge. Entry to the tank is limited to openings (risers) in the tops of the tanks. Each tank contains 5 to 10 existing risers which may be utilized. The present techniques considered most applicable for removal of sludge from SRP tanks are hydraulic resuspension of the sludge with liquid jets and chemical dissolution of the unslurried residue. In both cases, the resuspended or dissolved sludge would be removed from the tanks by separate mechanical pumps or jets. In genera1, the hydraulic techniques are envisioned for initially removing the most of the sludge. Chemical techniques would be more applicable for the removal of residual sludge that cannot be reached or removed by hydraulic slurrying. Chemical cleaning techniques are presently being developed at the Savannah River Laboratory (SRL). 
The hydraulic technique includes both the previously discussed high-pressure system and the newly developed low-pressure recirculating technique, which is the subject of this report.

\section{LOW-PRESSURE SLUDGE-SLURRYING CONCEPT}

The basic concept of the low-pressure sludge-slurrying technique is to immerse the slurrying pump in the sludge layer so that a recirculating mixture of sludge and supernate will serve as feed to the pump in place of fresh water (Figure 6). The highpressure, positive-displacement pumps in previous sludge-slurrying operations at SRP could not be operated and maintained in the radioactive environment of the sludge layer. However, a simpler low-pressure ( 100 psia) single-stage centrifugal pump was considered feasible as a recirculating pump for use in the sludge.

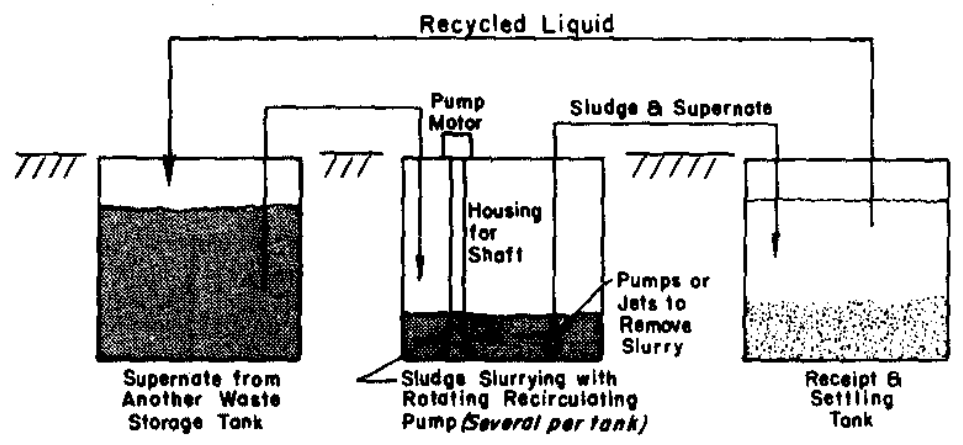

FIGURE 6. Low-Pressure Recirculating Technique

Initial studies were focused on the basic criteria for a low-pressure centrifugal pump designed to produce a liquid jet that would have a sludge-slurrying capacity at least equivalent to that of the previously demonstrated high-pressure jet. Two design factors considered potentially important for a liquid jet to be able to resuspend sludges were the turbulence level of the jet stream and the impact of the stream on the sludge. Both of these design parameters are dependent on the velocity of the stream. The ability of the $j$ et to keep the solids fluidized is also directly related to the velocity. Therefore, the velocity of the jet at any distance from the nozzle was taken as the measure of the slurrying efficiency of the jet.

A turbulent, high-velocity, free jet of fluid discharging from a round opening entrains fluid and expands after it leaves the outlet (References 3 and 4 and Figure 7). The jet consists of four general regions. First, the undisturbed core extends approximately five nozzle diameters along the jet axis. The 


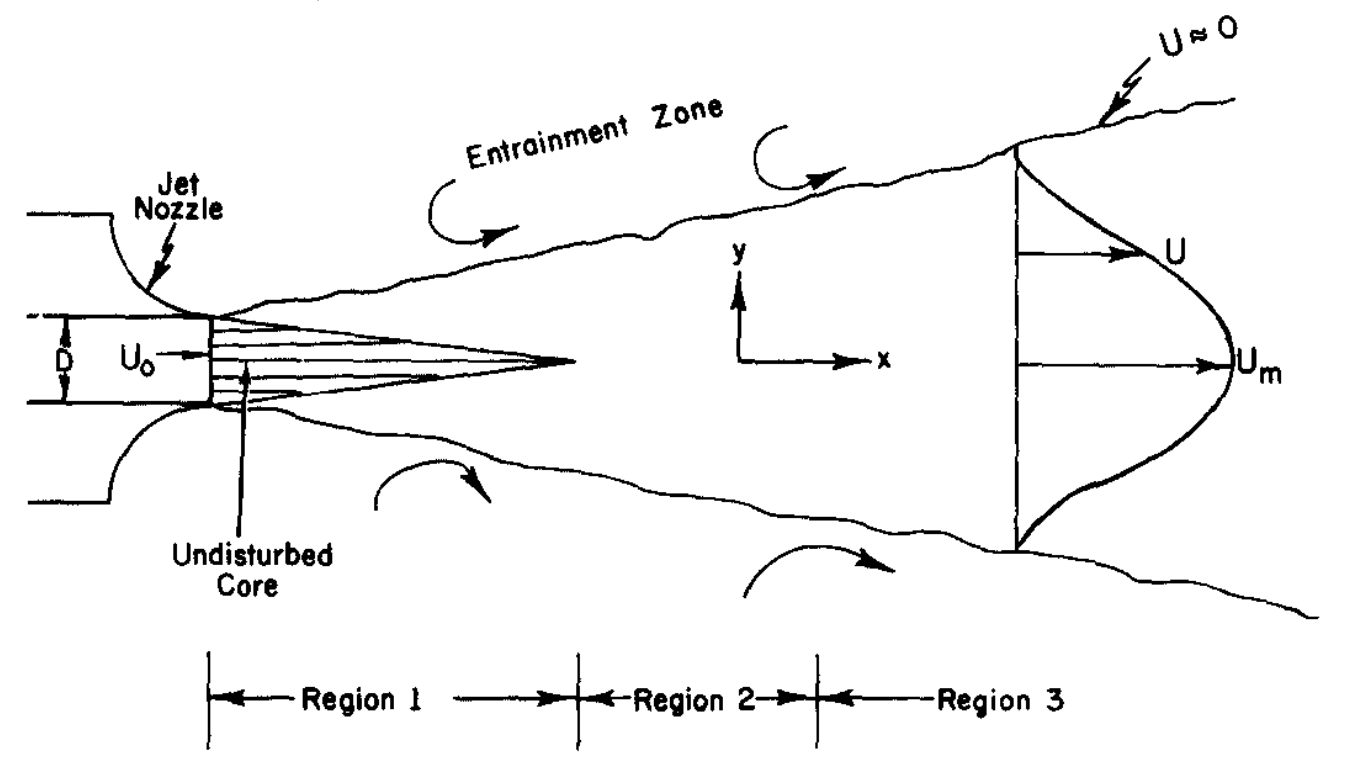

FIGURE 7. Turbulent Free Jet

velocity in this core is approximately equal to the initial discharge velocity. The second region is a transition zone that begins at the apex of the cone formed by the undisturbed core and terminates approximately eight nozzle diameters further along the axis. The principal region is the third region of established flow. In this region, velocity profiles are similar. The jet spreads at an angle of approximately 20 degrees. The fourth region is a terminal zone, where the jet velocity is very low and the $j$ et decays rapidly.

Virtually all of the slurrying action of the jet takes place in the region of established flow (Region 3 ). The distribution of velocity along the axis in this region for a single phase liquid or gas jet with no density gradients is given by

$$
\mathrm{U}_{\mathrm{m}} / \mathrm{U}_{\mathrm{O}}=\mathrm{C}_{1} \mathrm{D} / \mathrm{x}
$$

where $C_{1}$ is a constant (equal to approximately 6.5 for highvelocity water jets ${ }^{4}$ ) and $U_{m}, U_{0}, D$, and $x$ are defined as shown in Figure 7.

The radial distribution of axial velocity is correlated by an equation of the form ${ }^{3}, 4$

$$
\mathrm{U} / \mathrm{U}_{\mathrm{m}}=\mathrm{e}-\mathrm{C}_{2}(\mathrm{r} / \mathrm{x})^{2}
$$

where $C_{2}$ is a constant (equal to approximately 40 ), ${ }^{3} \mathrm{r}$ is radius, and $\mathrm{x}$ is horizontal distance. 
Substituting Equation 1 into Equation 2, one obtains

$$
\mathrm{U}=\left[\left(\mathrm{C}_{1} / \mathrm{x}\right)\left(\mathrm{U}_{\mathrm{O}} \mathrm{D}\right)\right] \mathrm{e}-\mathrm{C}_{2}(\mathrm{r} / \mathrm{x})^{2}
$$

Inspection of Equation 3 shows that the velocity of a jet at any point $(x, r)$ in the region of established flow is defined by the product of $U_{0} D$ and is directly proportional to $U_{0} D$. $A$ high-pressure, positive-displacement pump produces a much higher throat velocity, $\mathrm{U}_{0}$, than a single-stage centrifugal pump. lowever, this can be compensated by increasing the nozzle diameter, D. The positive-displacement pumps used previously at SRP operated at a pressure of $\sim 3000$ psia and gave a throat velocity of $2650 \mathrm{ft} / \mathrm{sec}$ through a 0.25 -inch-diameter opening in the nozzle. ${ }^{2}$ A single-stage centrifugal pump was procured with an operating pressure of 2100 psia to give a throat velocity of $100 \mathrm{ft} / \mathrm{sec}$ through a 1.5 -inch-diameter nozzle. The product $\left(\mathrm{U}_{\mathrm{O}} \mathrm{D}\right)$ is the same for both systems $\left(\sim 14 \cdot \mathrm{ft}^{2} / \mathrm{sec}\right)$. Therefore, according to Equation 3 , the jet produced by the recirculating centrifuga 1 pump should be identical to the jet produced by the high-pressure, positive-displacement pump in the region of established flow.

The initial flow cate of the low-velocity jet from the centrifugal pump is much higher than for the original high-pressure system (600 gpm vs. $100 \mathrm{gpm}$ ). The high-velocity jet entrains a much larger volume of fluid before flow is established. Less entrainment takes place for the low-velocity jet. This results in a reduced power requirement for the low-velocity jet relative to the high-velocity jet. The required power for either jet can be evaluated by the Bernoulli equation for the energy of the outlet stream as given below:

$$
\begin{aligned}
\text { Power }= & \text { (Mass-Flow-Rate through Nozzle) } \\
& x \text { (Energy-per-Unit-Mass at Outlet) } \\
= & {\left[(\pi / 4) D^{2}\right] \quad\left(U_{o} \rho\right)\left(U_{o}{ }^{2} / 2 g_{c} \eta\right) }
\end{aligned}
$$

where $\rho=$ fluid density

$$
\begin{aligned}
g_{c} & =\text { gravitational conversion factor } \\
\eta & =\text { pump efficiency }
\end{aligned}
$$

For the case of identical jets in the region of established flow,

$$
\mathrm{U}_{\mathrm{O}} \mathrm{D}=\mathrm{K}
$$

where $K$ is a constant. 
Power $=\frac{\pi \rho K^{2}}{8 g_{c} \eta}\left(U_{o}\right)$

or

Power $=\frac{\pi \rho K^{3}}{8 g_{c} n}(1 / D)$

Equations 6 and 7 show that the power required to produce a fully established jet increases directly with the jet velocity at discharge (neglecting variations in pump efficiency). Because the initial velocity of the jet from the low-pressure pump is only approximately one-sixth of that of the high-pressure system, the power requirement is a1so only approximately one-sixth of that for the high-pressure system - another advantage for the lowpressure centrifugal pump.

The additional power needed for the high-pressure system is dissipated near the nozzle in the transition region (Region 2).

Although the power input and dissipation characteristics for the two types of systems are quite different, the momentum of the jets would be the same down the axis because most of the momentum of the jet is conserved as it travels through the fluid.

The total momentum at the discharge of the jet is given by

$$
(\rho \pi / 4)\left(U_{0} D\right)^{2}
$$

Therefore, when the term $U_{0} D$ is fixed, the momentum of the jet is also fixed. The jet pattern in the region of established flow is the same for all jets with the same nozzle momentum because the term $U_{0} D$ is the same.

\section{EQUIPMENT AND TEST FACILITY}

\section{Centrifugal Pump}

The single-stage, volute-type, centrifugal pump (BinghamWillamette Co., Portland, Oregon) has a capacity of $600 \mathrm{gpm}$ for each of two 1.5-in.-diameter nozzles positioned $180^{\circ}$ apart (Figure 8). This 3.5-ton pump was designed to fit into existing 2-ft-diameter tank risers; it is 32.2 feet long and has a maximum diameter of 22.5 inches. The pump and motor unit is mounted on a turntable with a maximum rotational speed of $0.5 \mathrm{rpm}$ (Figure 9). 


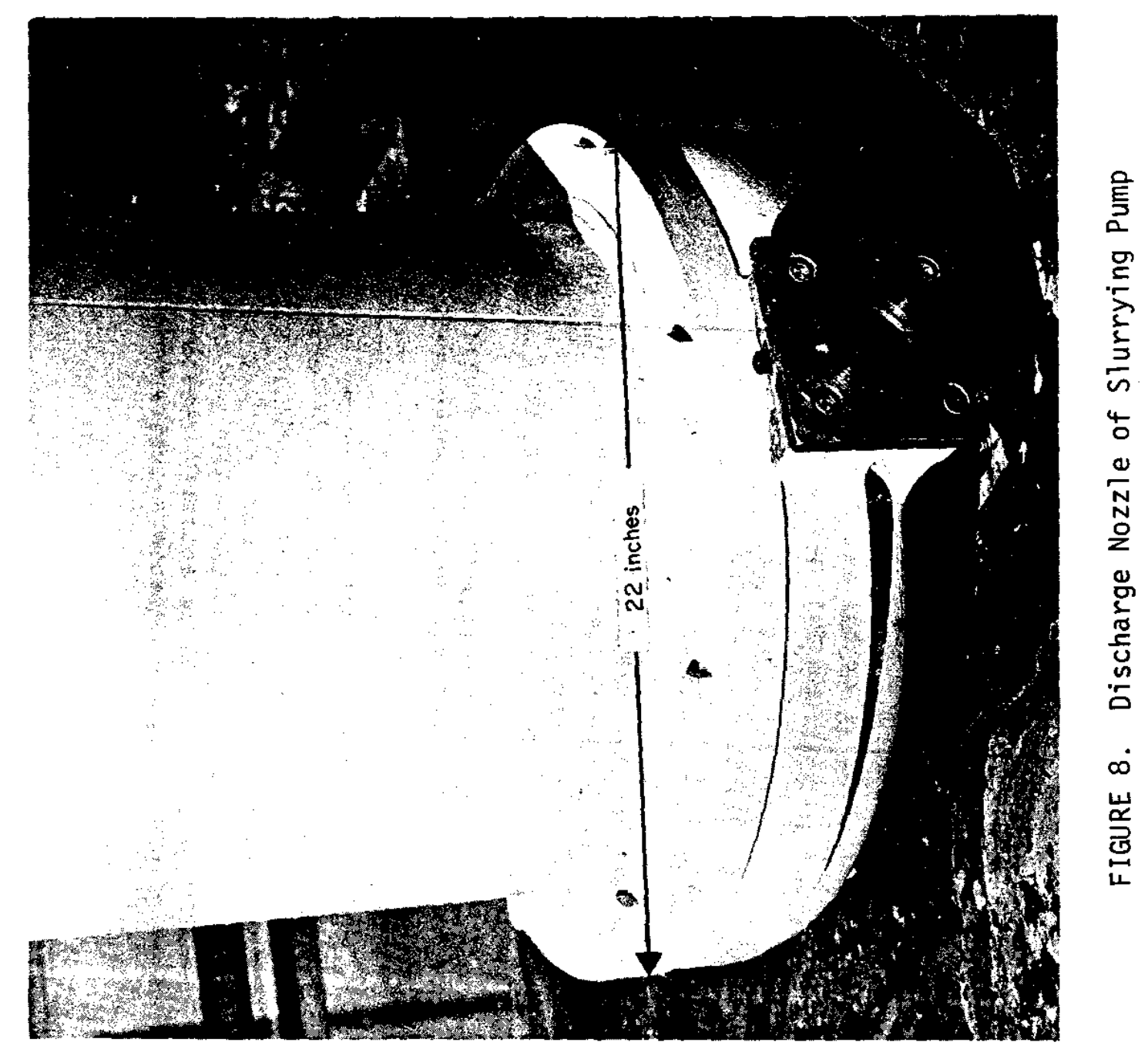




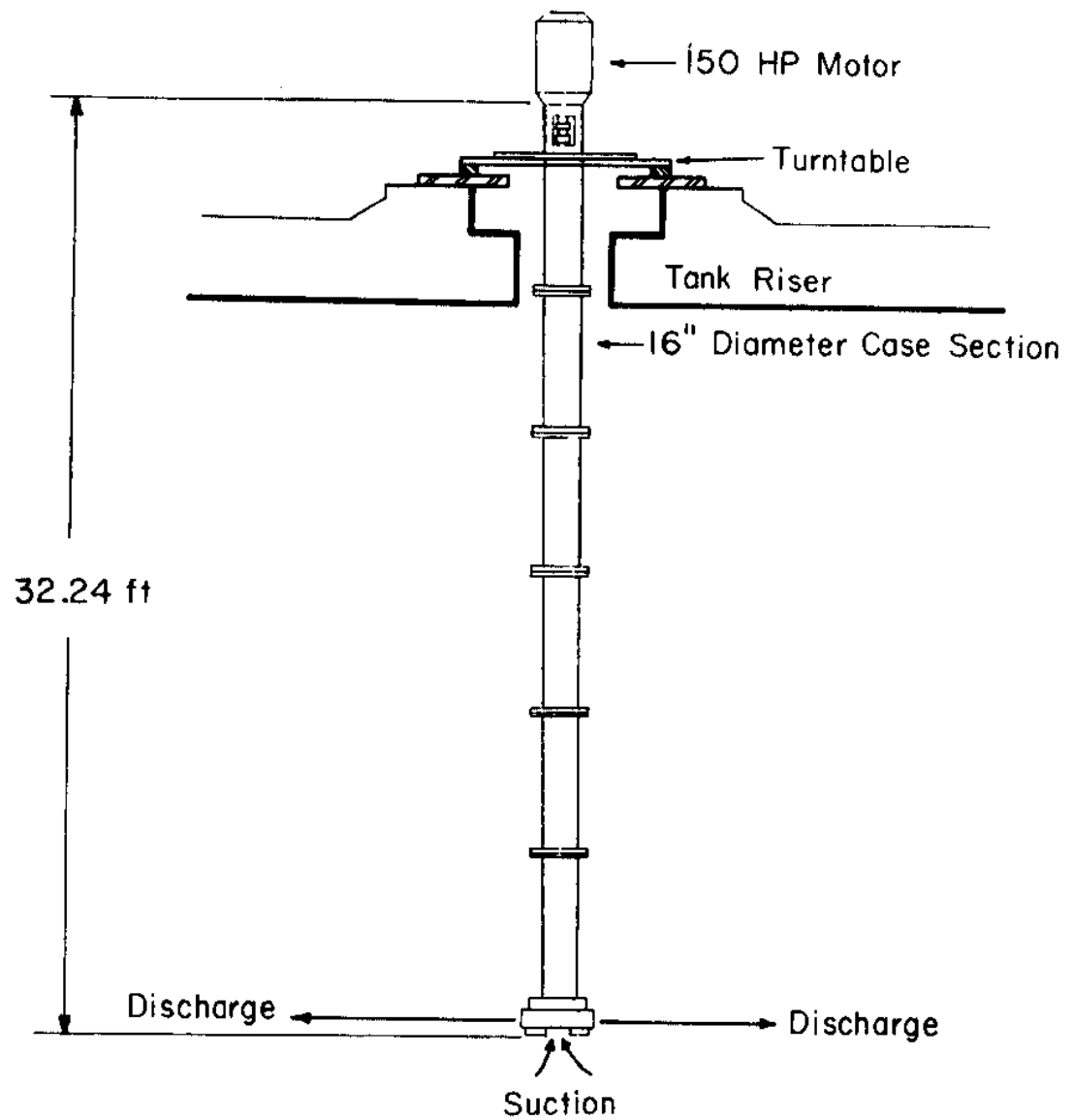

FIGURE 9. Proposed Mounting of Slurrying Pump in Waste Tank Riser

The pump consists of 6 casing sections, each 53 inches long and 16 inches in diameter. The cases are flanged on both ends and provide rigid structural support. Each casing section contains a 4-in.-diameter cooling water pipe and a shaft alignment bushing (Figure 10). The shaft alignment bushings are cooled and lubricated by water flowing ( $\sim$ l gpm) through triangular grooves which are cut in the bushings parallel and adjacent to the pump shaft (Figure 11).

The pump is constructed of carbon steel, except for the stainless steel shaft and impeller. The shaft consists of three 10-foot sections, each 1.5 inches in diameter. The 15-in.-diameter impeller is a 4-vane semi-open type (Figure 12).

The pump is driven by a 150-hp induction motor. The motor operates on 460-volt, 3-phase, alternating current and is controlled at speeds between 600 and $1800 \mathrm{rpm}$ by a variable speed control unit. Electrical power is fed to the rotating motor and pump through a slip-ring device (Figure 13). 


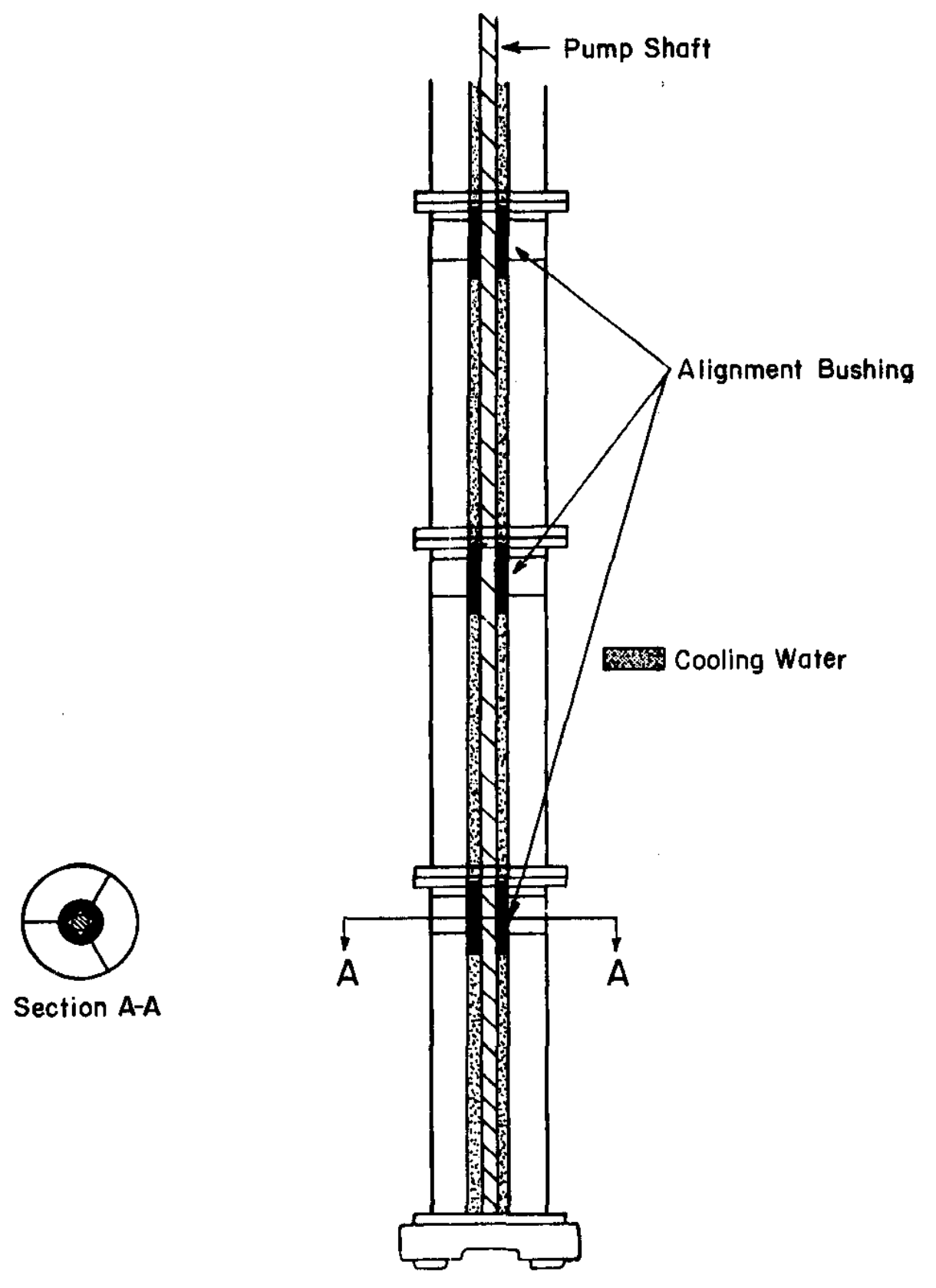

FIGURE 10. Cooling Water Pipe and Shaft Alignment Bushings in Case Sections of Slurrying Pump 


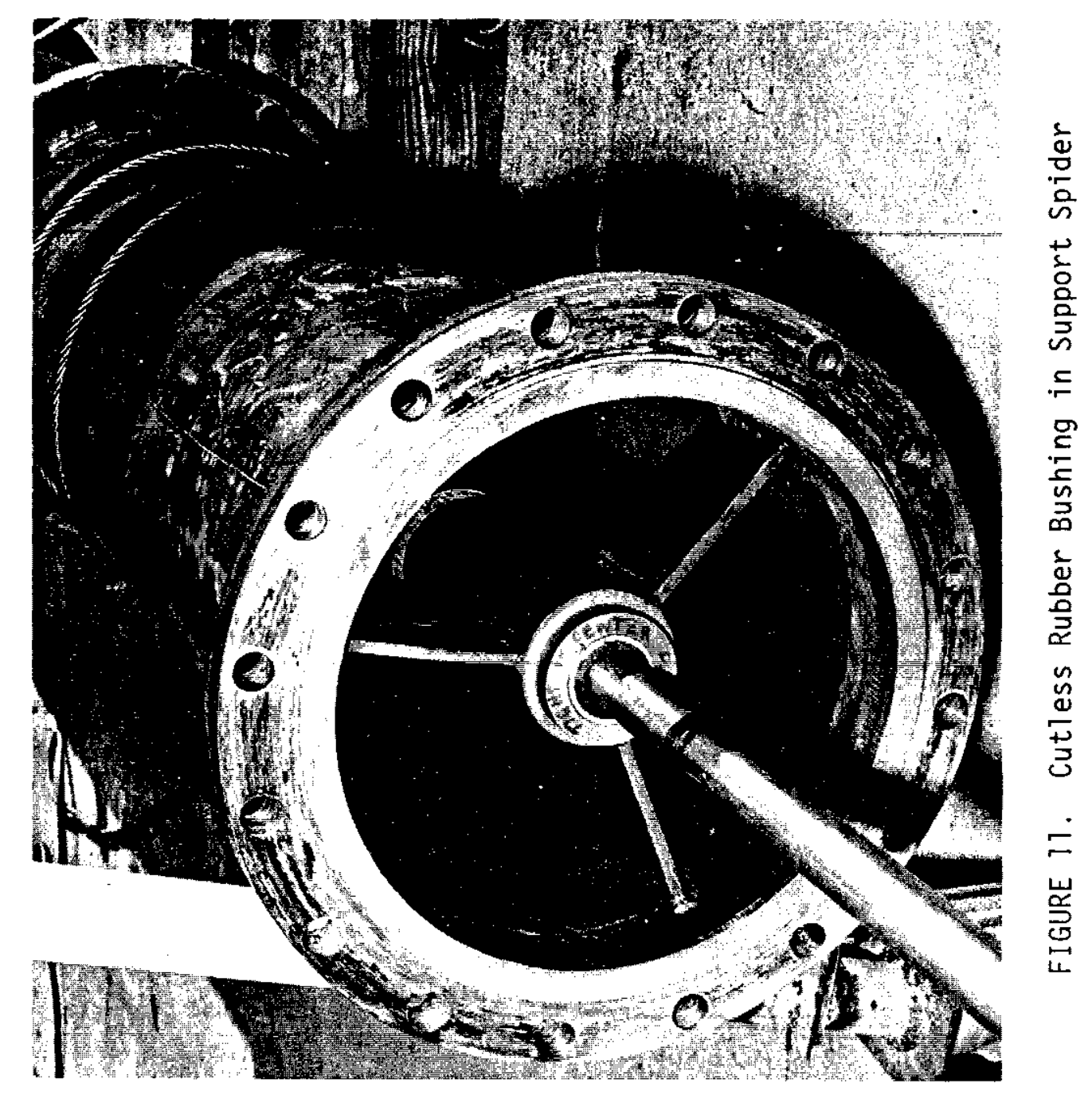




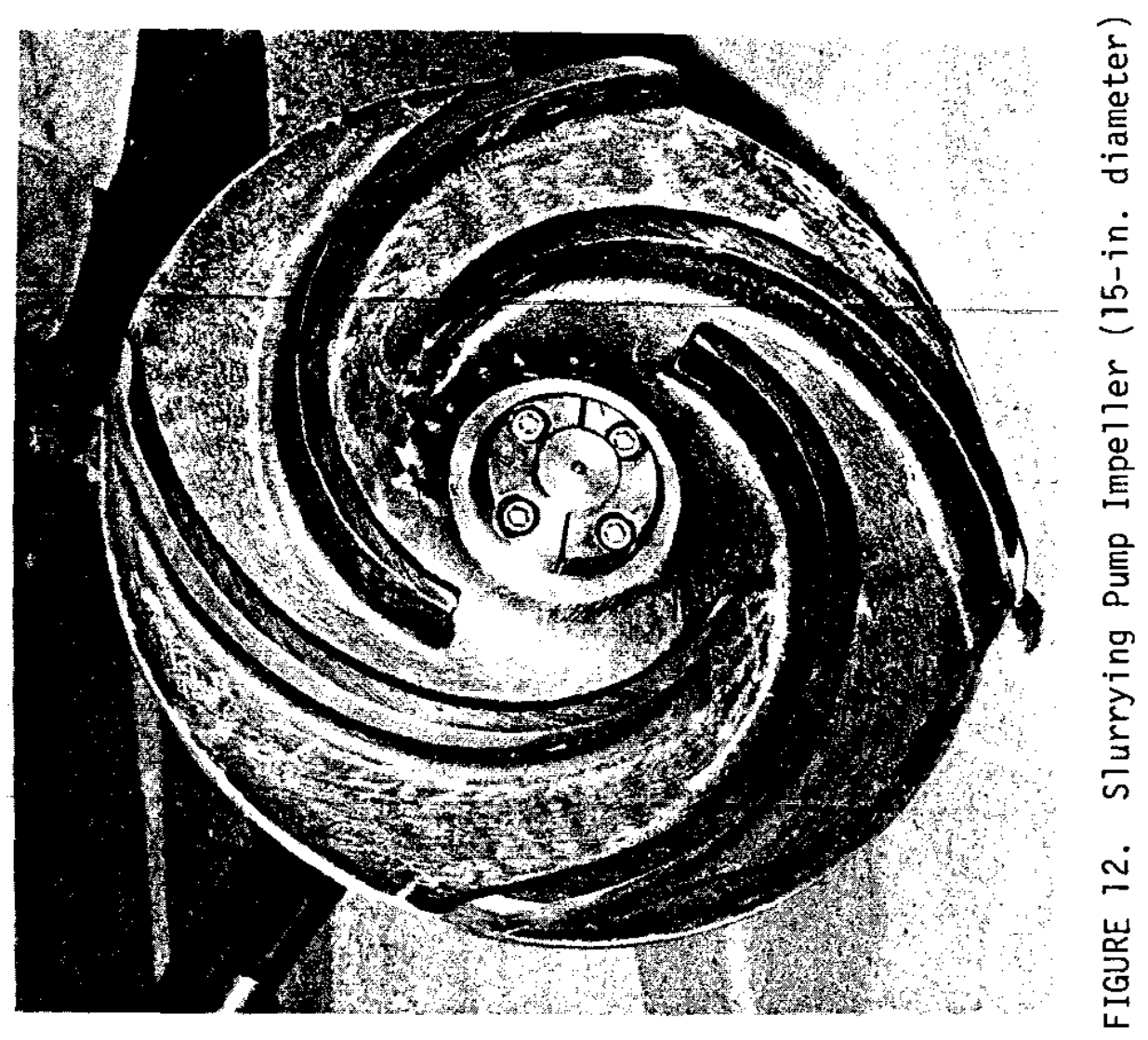




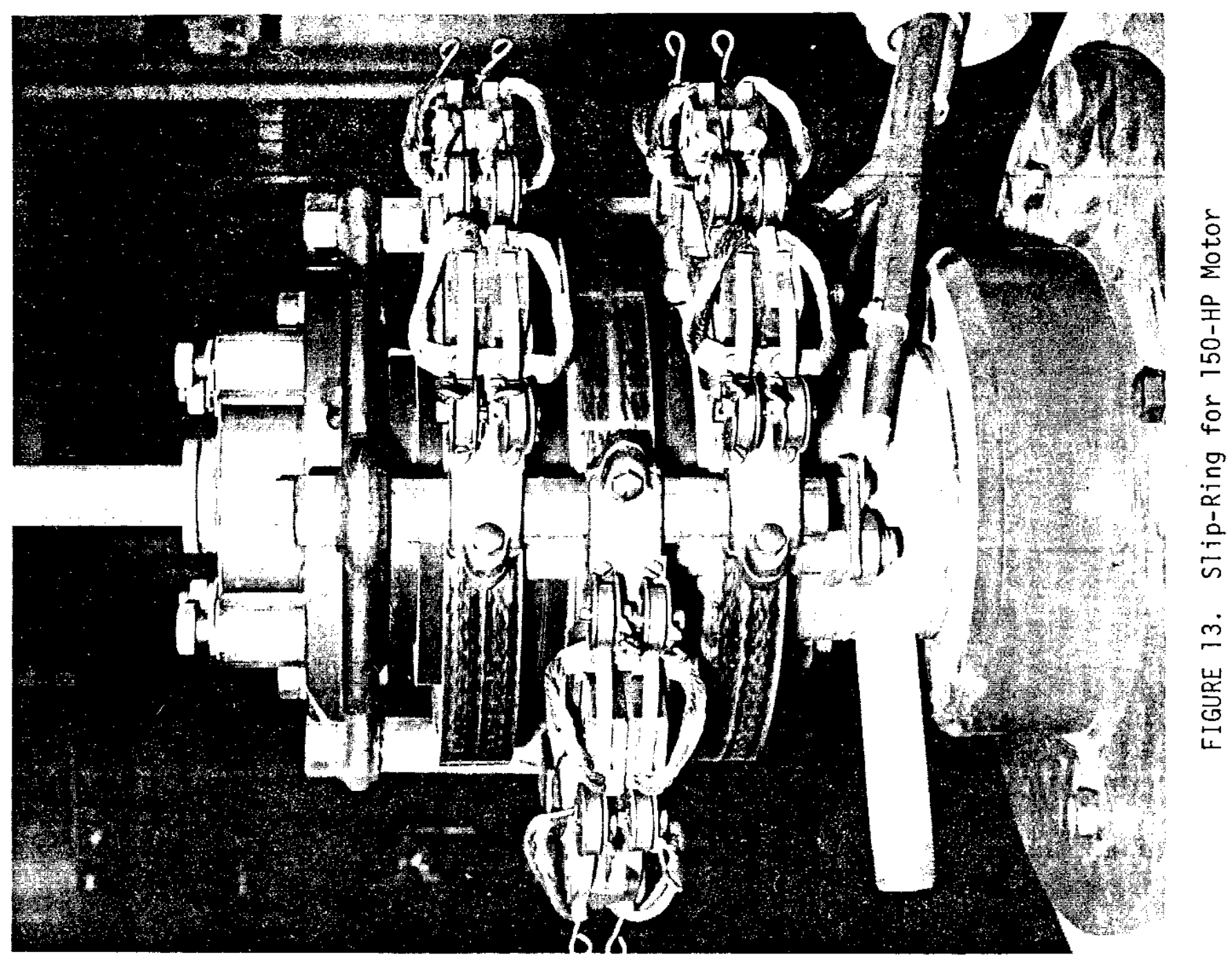




\section{Test Facility}

The semiworks test facility consists of a half-tank mockup, pump support tower, and control room. The pump is mounted on a platform supported 33 feet above the tank bottom by the tower (Figure 14). The platform has a turntable which can rotate the pump and motor at 0.2 to $0.5 \mathrm{rpm}$ (Figure 15). The half-tank mockup of a Type I high activity waste tank has horizontal cooling coils and six roof-support columns to simulate the actual waste tank (Figure 16).

\section{RESULTS OF FEASIBILITY TESTS}

The slurry pump tests verified the concept of using lowpressure recirculating centrifugal pumps to slurry radioactive sludge in the SRP waste tanks. Tests were carried out in the same $1 / 2$ tank mockup used previously for testing the high-pressure system, and the test results were essentially the same. Kaolin clay was used to simulate radioactive sludge, and water was used to simulate supernate. The tests were conducted with a water-tokaolin volume ratio of at least 1-to-1 or greater. The characteristics of the pumps and sludge removal operating procedures were studied to determine the best methods for slurrying the kaolin (sludge).

The Bingham slurry pump characteristics were verified with the half-tank mockup filled with water. The performance curves are shown in Figures 17 and 18 . The figures illustrate the relationships between discharge rate, nozzle pressure, and impeller speed. The pump speed was varied between 600 and $1800 \mathrm{rpm}$.

The sludge-slurrying ability of the Bingham pump was determined by observing simulated waste-tank sludge-removal operations. To simulate 1.5 feet of sludge, 40 tons of dry kaolin clay was added to the half-tank mockup. Water was added to the tank to a total depth of 3 feet. The slurry pump was then operated for a specified time period and then the slurry mixture of kaolin and water was removed. The cleaning pattern of the slurry pump was judged by the depth and location of the kaolin clay on the tank bottom after the slurry was removed. The slurrying ability of the pump was described by the effective cleaning radius, which was defined as the radial distance on the tank bottom from the impeller center that had a layer of kaolin less than $1 / 8$ of an inch thick after the slurry was removed. The above definition did not apply to areas in the wake of obstacles such as the roof support columns. Kaolin clay was occasionally removed from behind the roof support columns located near the curved tank wall because the slurry circulated along the wall with sufficient velocity to maintain the kaolin in suspension. 


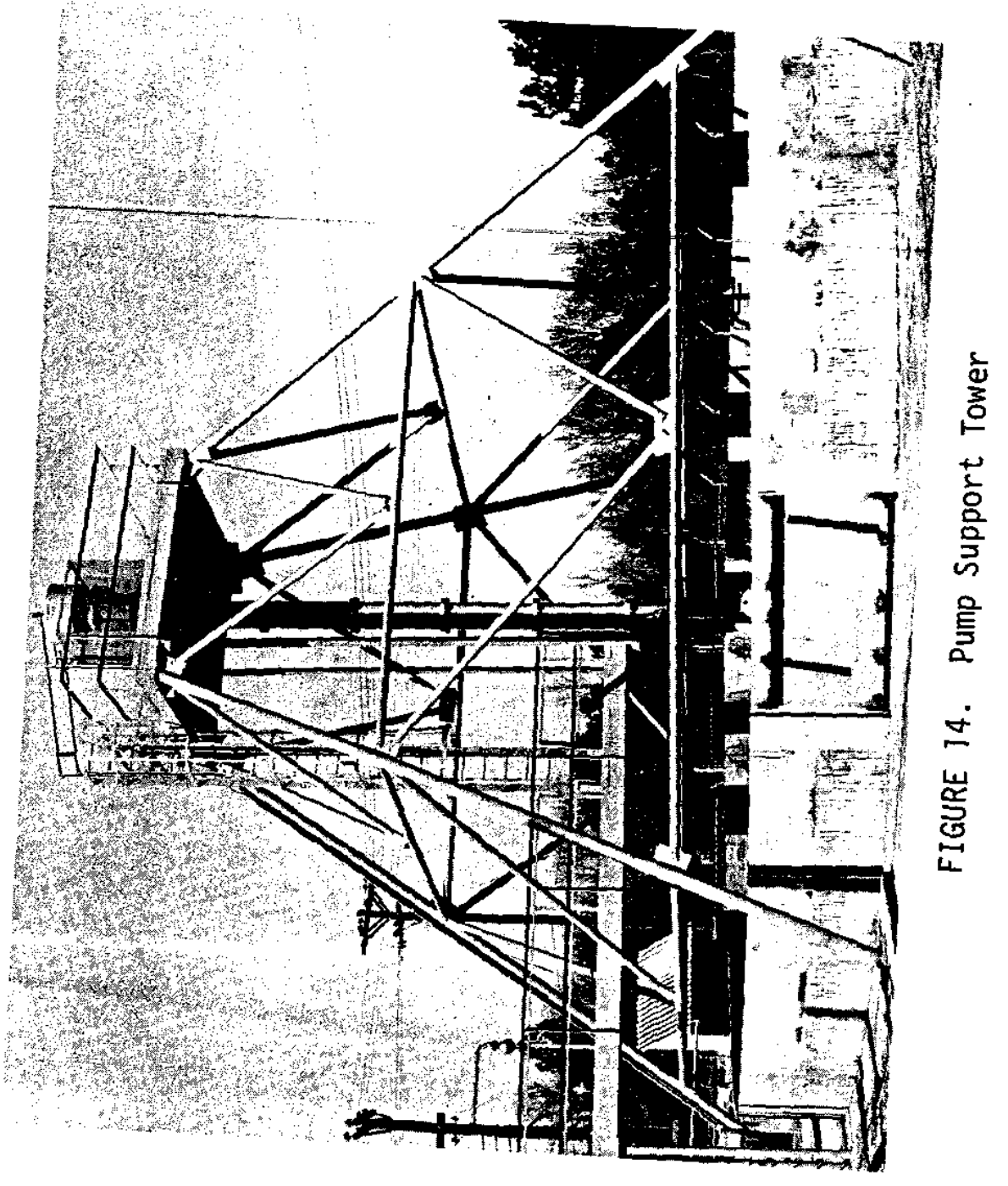




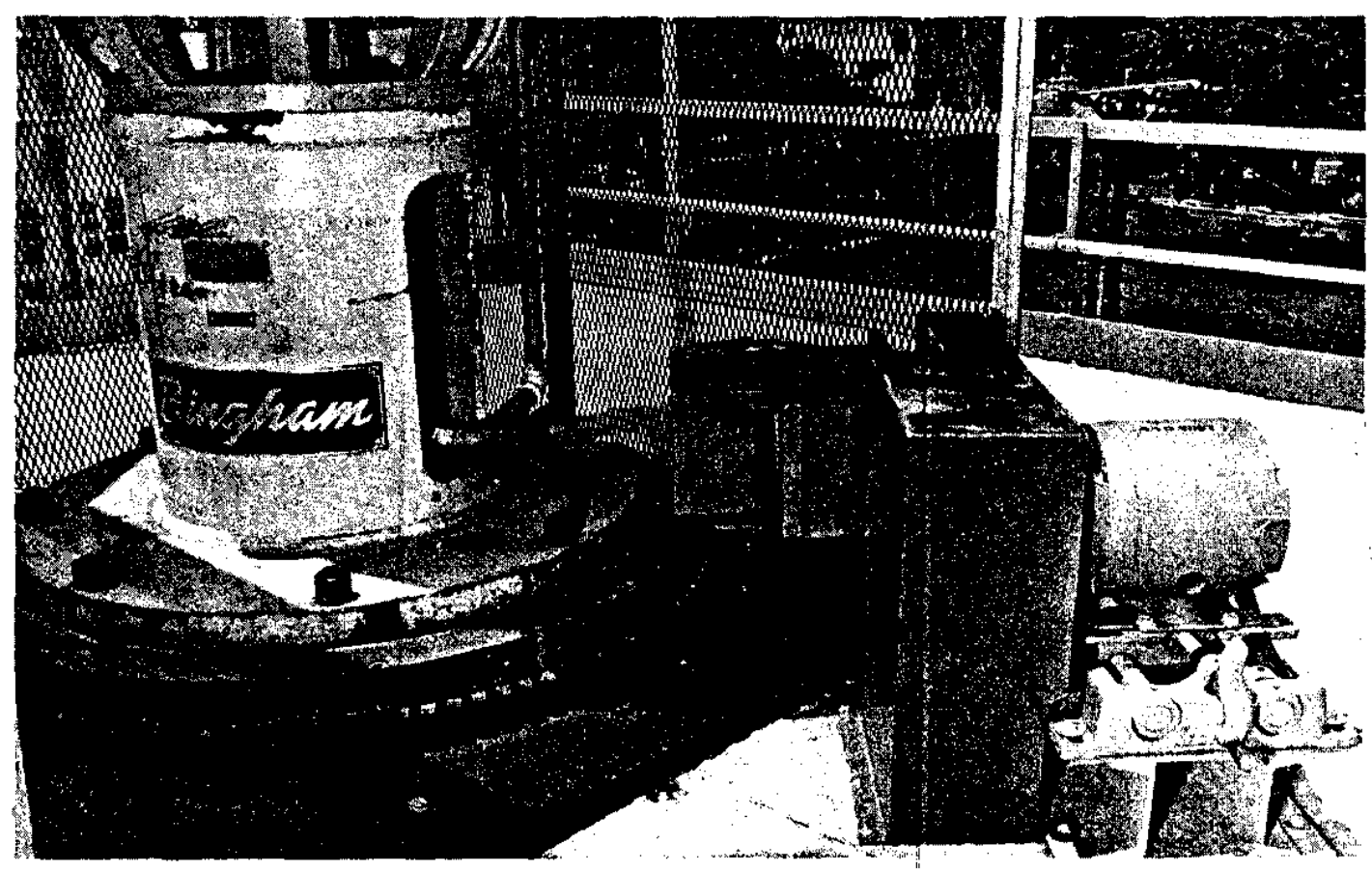

FIGURE 15. Turntable and Pinion Drive

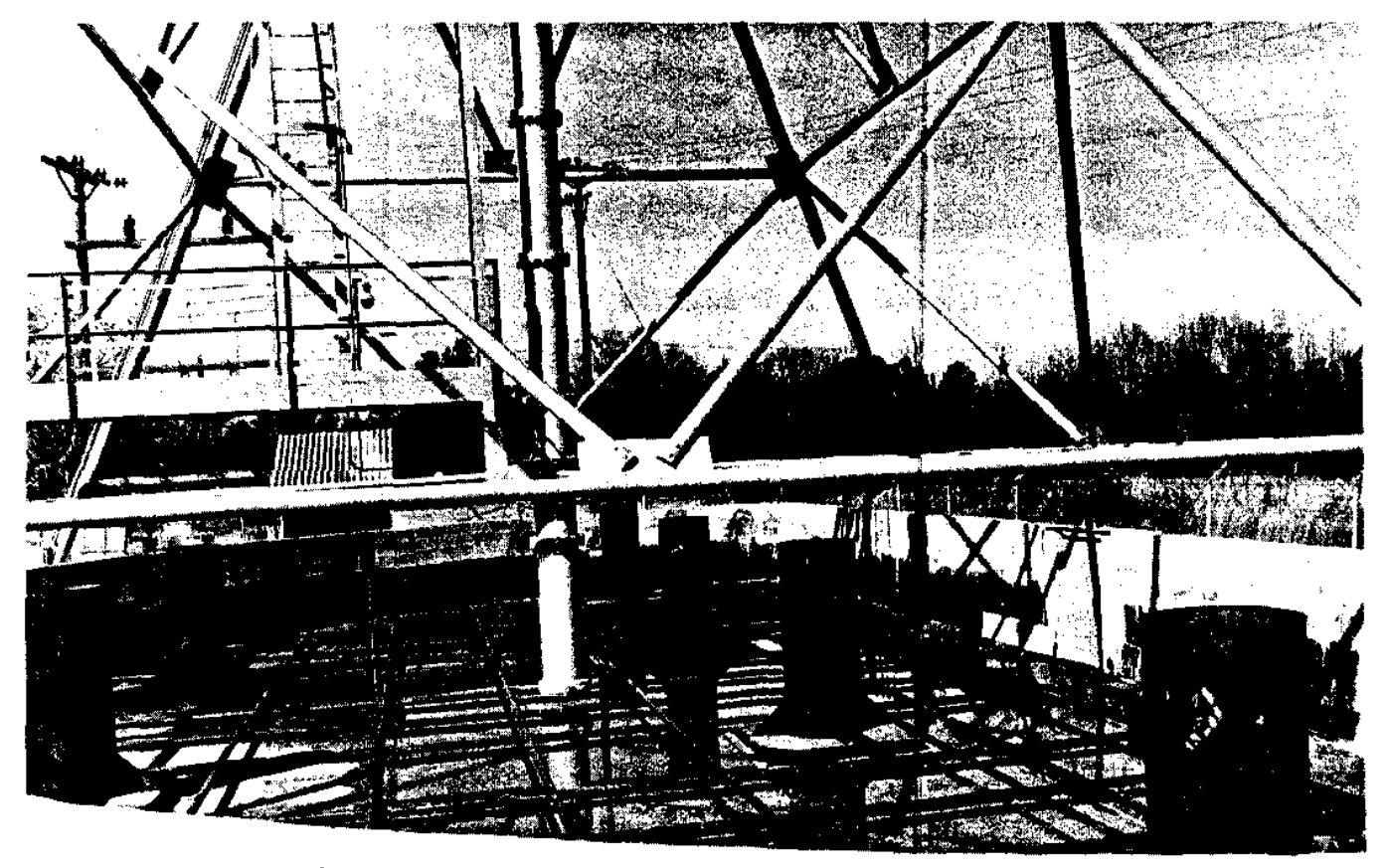

FIGURE 16. Interior of Half-Tank Mockup 


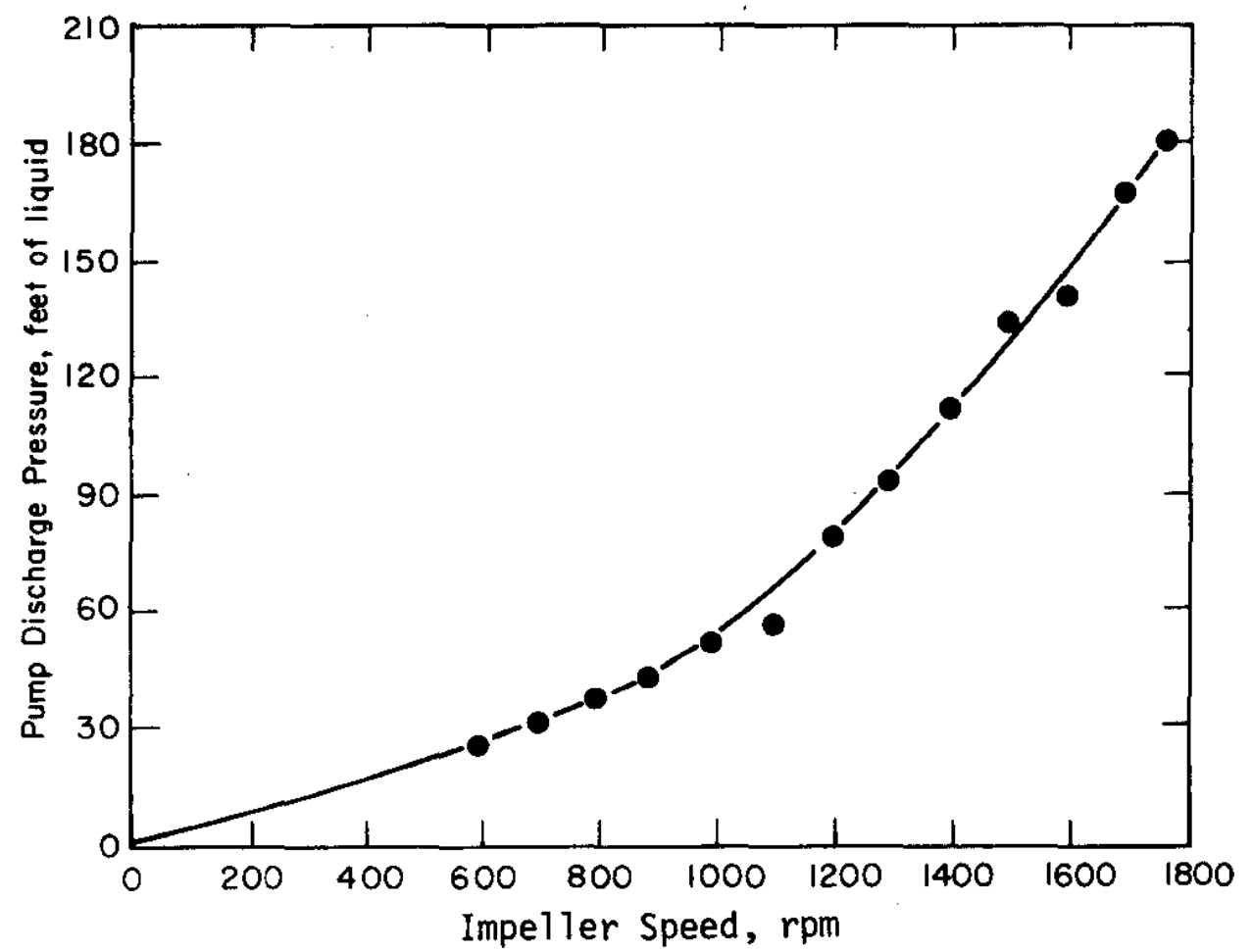

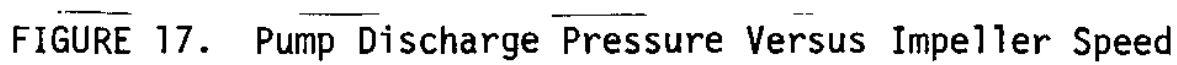

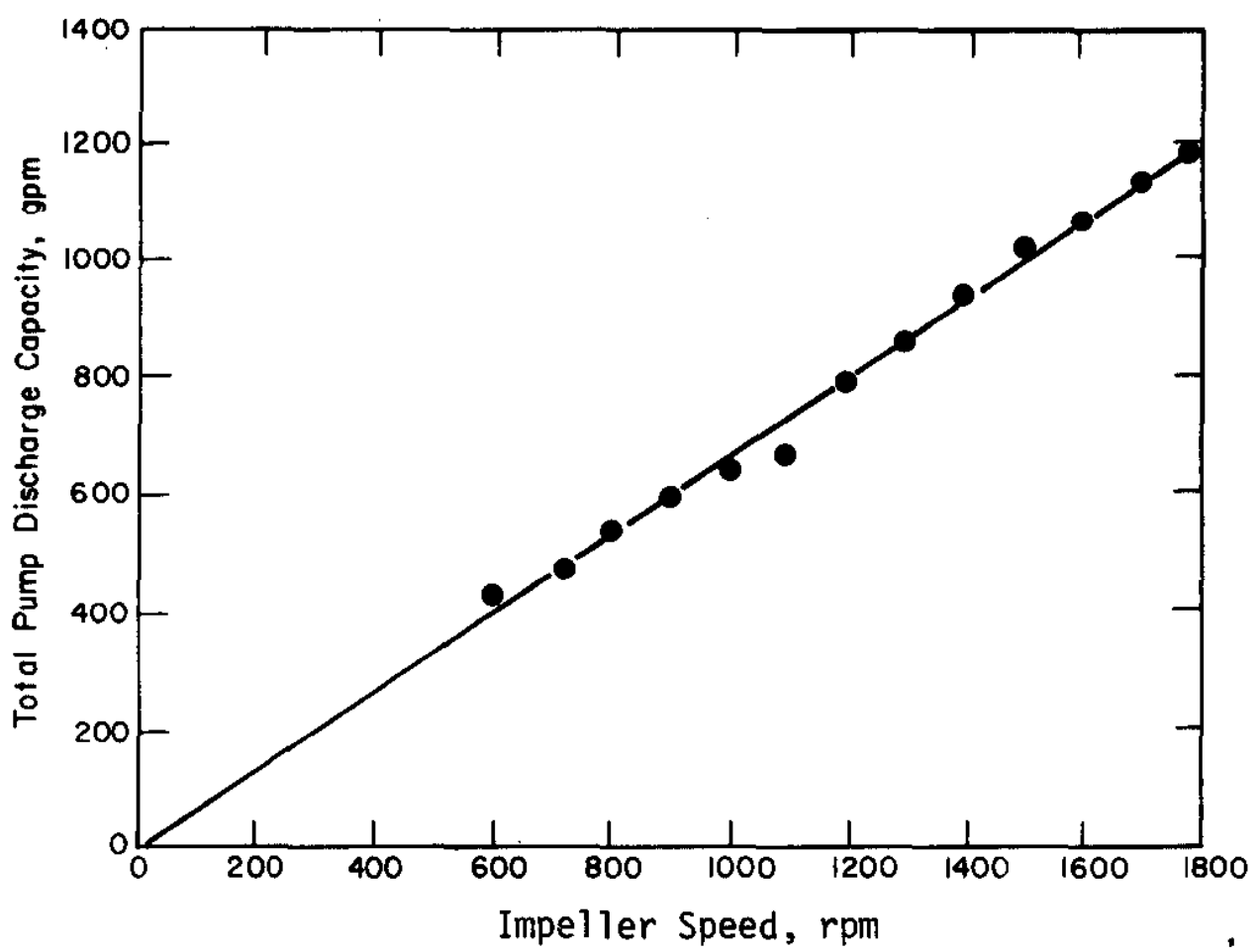

FIGURE 18. Pump Discharge Capacity Versus Impeller Speed 
The effective cleaning radius of the slurry pump was $\sim 20$ feet at an impeller speed of $1800 \mathrm{rpm}$ as was predicted based on previous tests with the high-pressure system. The effective cleaning radius was directly proportional to the product of the nozzle velocity and diameter $\left(U_{O} D\right)$ as shown in Figure 19. The discharge jets from the slurry pump created superficial mixing beyond the 20-foot cleaning radius. The agitation from the jet beyond the effective cleaning radius was insufficient to prevent the kaolin from settling to the tank bottom. Consequently, areas of tank not influenced by the slurry pump tended to increase in depth of kaolin from settling of kaolin during the slurry period. Figure 20 shows the location of kaolin after a typical slurry test. Figures 21,22 , and 23 are photographs of the kaolin formations shown in Figure 20 in the upper, center, and lower portions, respectively, of the mockup tank.

In one test, all of the kaolin was added to one corner of the half-tank mockup as a large mound. The results of this test were roughly the same as for tests with clay added as a uniform initial layer. Clay was moved from the mound and settled outside of the 20 -foot cleaning radius resulting in a symetrical cleaning pattern equivalent to that obtained in tests with the clay evenly distributed initially.

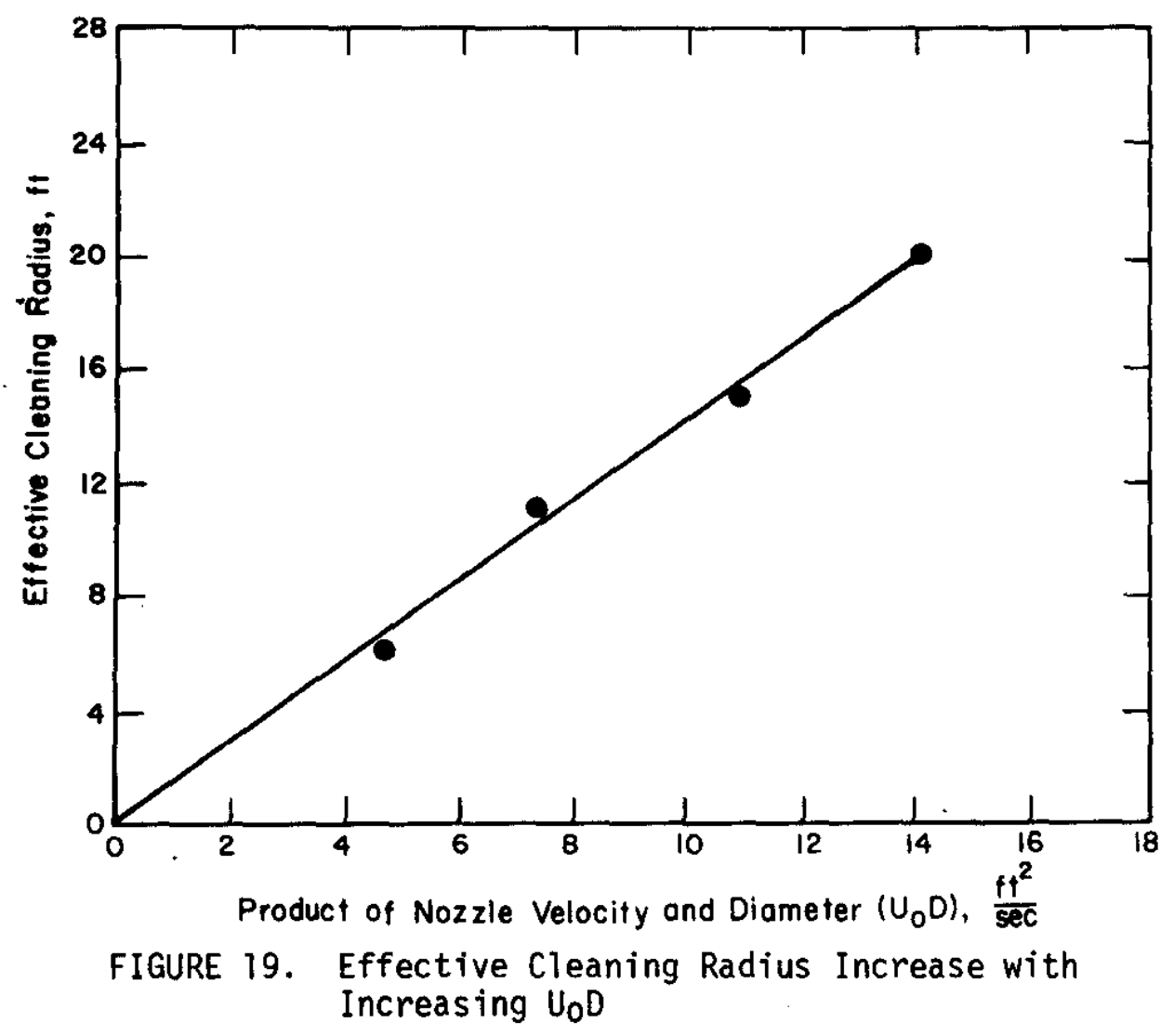




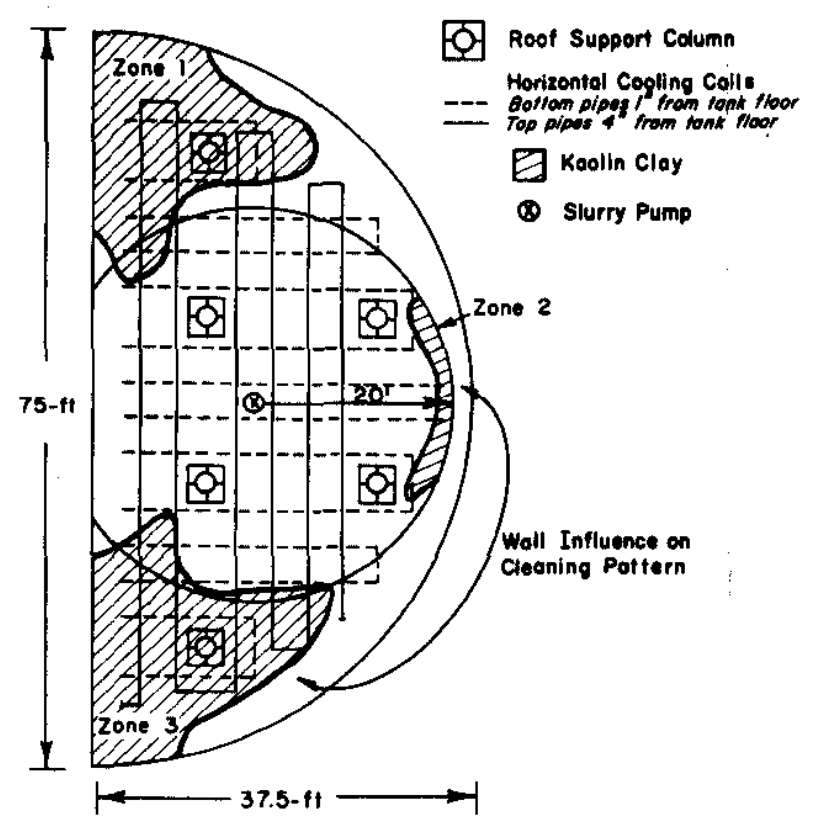

FIGURE 20. Cleaning Pattern of Slurry Pump in Half-Tank Mockup

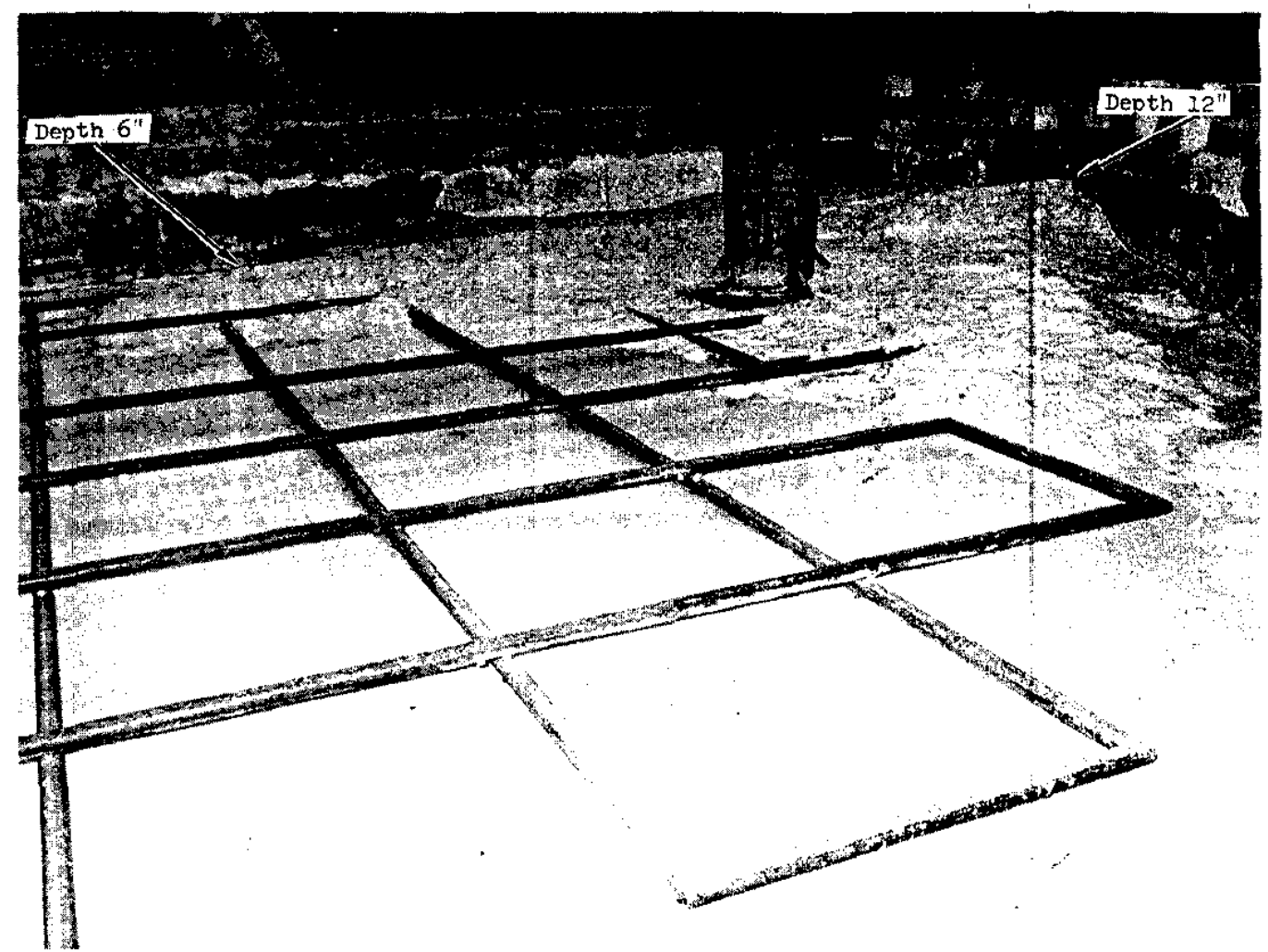

FIGURE 21. Kaolin Formation After Slurry Operation - Zone 1 


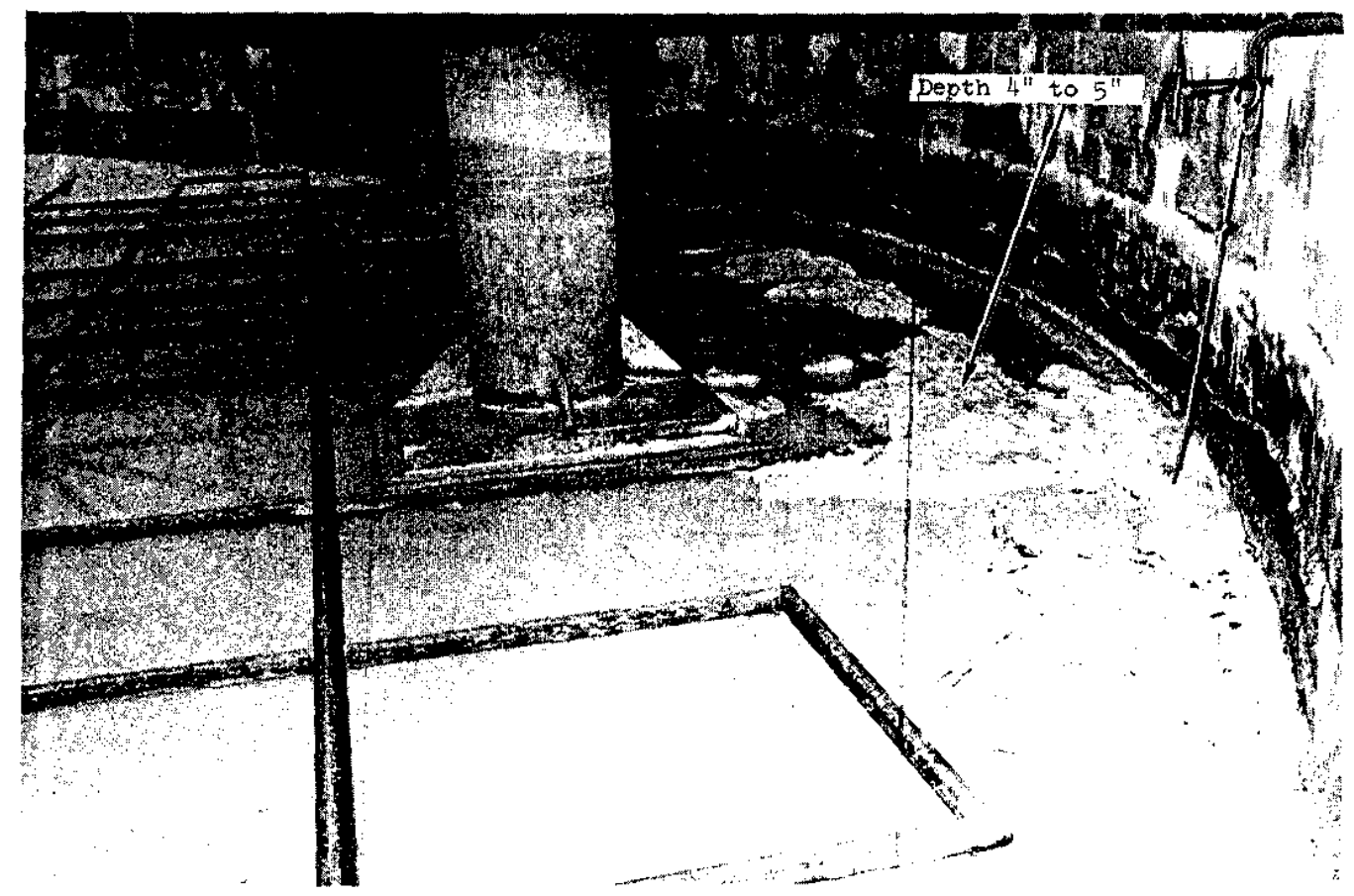

FIGURE 22. Kaolin Formation After Slurry Operation - Zone 2

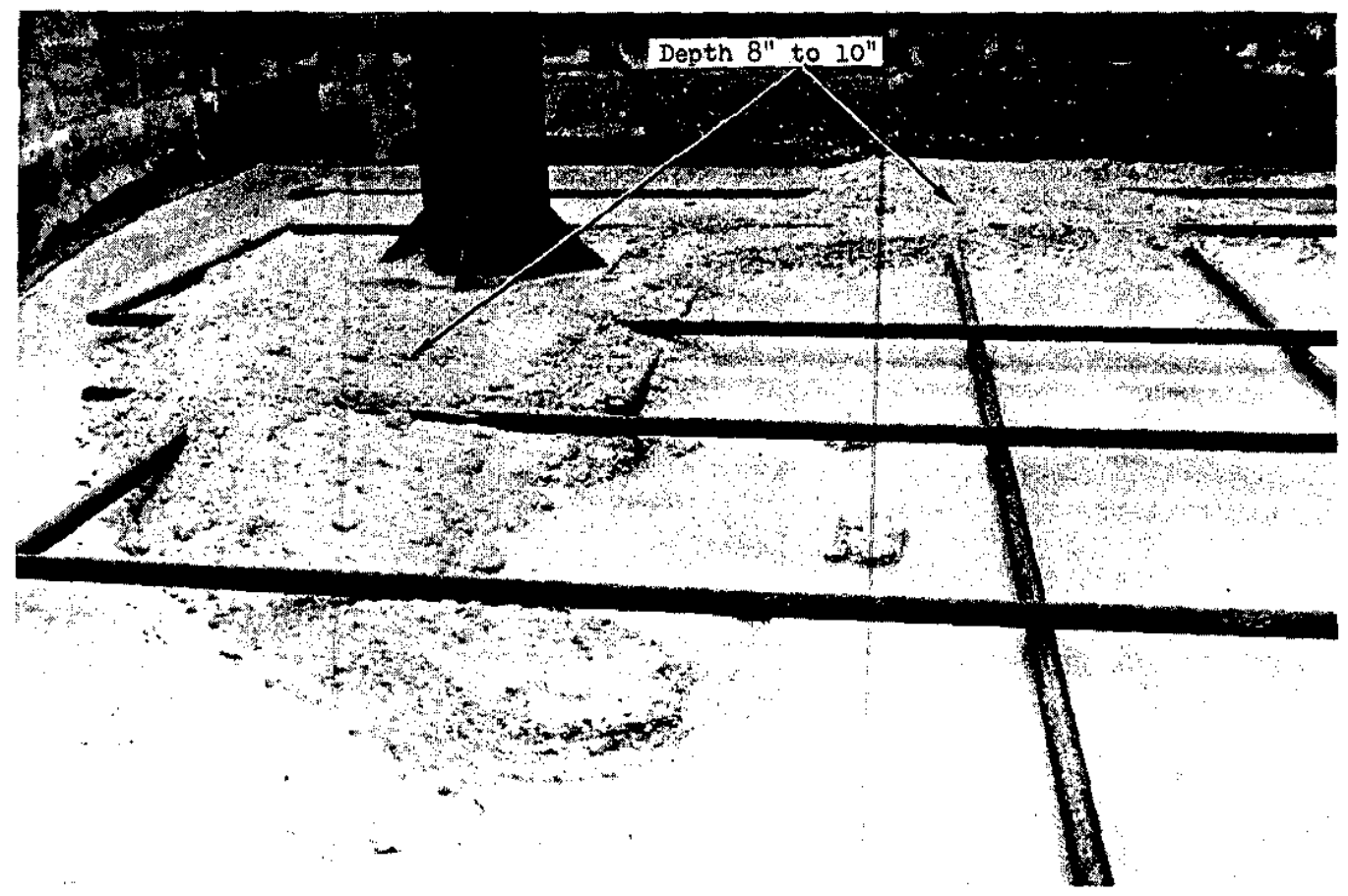

FIGURE 23. Kaol in Formation After Slurry Operation - Lone $s$

1. 
The initial slurry step should have a minimum of a 1-to-1 volume ratio of supernate-to-sludge to ensure the slurry pump creates a mixture of sludge and supernate that can be removed by slurry transfer pumps. The evaluation of the kaolin slurrying procedures indicated that at least 3 slurry steps are required. However, repetition of the slurrying steps on the kaolin clay after four slurry periods were ineffective in suspending additional kaolin. The effectiveness of the slurry pump for suspending kaolin outside the effective cleaning radius decreased with subsequent tank washings or slurry steps. However, if additional washings of the waste tank are desired, the liquid level in the tank should be kept to a minimum with respect to the slurry pumps to maintain the maximum amount of agitation in the tank.

Slurry periods of greater than 75 hours were studied. After 50 hours of slurrying, no significant changes occurred in either the effective cleaning radius or the amount of kaolin suspended in the water. However, the effect of the circulation pattern on the kaolin that had existed near the curved wall was more distinct. The circulation pattern has sufficient velocity as it moves along the curved wall to erode the kaolin and keep the kaolin from settling within $\sim_{1} \mathrm{ft}$ of the wall. The influence of the curved wall on the cleaning pattern is shown in Figure 20.

The slurry pump was rotated at $1 / 3 \mathrm{rpm}$ during the tests, and the direction of rotation was periodically reversed. The reversing of direction of rotation changed the eddy patterns that existed in the wake of the objects in the tank. The change in eddy patterns assisted in preventing the kaolin from settling around obstacles in the tank.

\section{CONCLUSIONS}

The results of the siurry pump tests have shown that the concept of using low-pressure, recirculating, centrifugal pumps to slurry radioactive sludge in waste tanks is practical. The developmental Bingham sludge-slurrying pump has an effective cleaning radius of $\approx 20$ feet at $1800 \mathrm{rpm}$ with a 1-to-1 volume ratio of kaolin clay-to-water. The jet produced by the recirculating system is esscntially the same as that produced previously by the high-pressure jet. The number of slurry pumps needed per waste tank to suspend the sludge will depend on the type of tank and the location of existing risers. 
The length of time for a slurry step should be 50 hours. Furthermore, reversing the direction of rotation of the pump increases the rate at which sludge is removed from behind larger obstructions. The slurry pump must be operated during the slurry removal process to provide agitation to prevent the sludge from settling during the slurry removal operation.

The effective cleaning radius was directly proportional to the $U_{O} D$ product, which is, in turn, a direct measure of $j e t$ velocity in the region of established flow (Region 3). Extended slurrying tests showed that the cleaning pattern did not change after three slurrying steps of 50 hours each with a 1-to-1 volume ratio of clay-to-water. Larger pumps that will give larger values of $U_{O} D$ will be tested in the SRL mockup facility to determine if the effective cleaning radius can be increased.

\section{REFERENCES}

1. Integrated Radioactive Waste Management Plan, Savannah River Plant, Aiken, S. C. USERDA Doc. SRO-TWM-76-1. Savannah River Operations Office, Aiken, South Carolina (1976).

2. A. J. Hil1, Jr. Removal of Sludge from High Activity Waste Tanks. USAEC Report DP-1093, E. I. du Pont de Nemours \& Co., Savannah River Laboratory, Aiken, South Carolina (1967).

3. J. H. Perry, Ed. Chemical Engineers' Handbook. 4th Edition, pp 5-18, McGraw-Hi 11 Book Company, New York (1963).

4. N. S. Shashidhara and E. L. Bourrodimos. "Turbulence and Diffusion Investigations in a Submerged Axisymmetric Water Jet." Water Resources Bull. 11 (1), 77 (Feb., 1975). 